\title{
Os Deslocamentos na Colômbia por fatores ambientais (2010-2012) ${ }^{1}$
}

The displacements in Colombia by environmental factors (2010-2012)

Laís Azeredo Alves²

\section{RESUMO}

O boletim tem como principal objetivo analisar a influência de fatores ambientais (especialmente mudanças climáticas) nos deslocamentos de indivíduos colombianos entre os anos de 2010-2012, destacando que, além do histórico conflito civil e da frágil situação social, outros elementos também estão motivando movimentos populacionais dentro e fora do país. Destacando-se, assim, a multicausalidade dos movimentos migratórios no país.

Palavras-chave: Deslocamentos populacionais; Mudanças Climáticas; Colômbia.

\begin{abstract}
The paper aims to analyze the influence of environmental factors (especially climate change) in displacement of Colombian individuals between the years 2010 to 2012, highlighting that, in addition to historical civil conflict and fragile social situation, other elements are also motivating population movements within and outside the country. Thus the migratory movements have multiple causes in the country.
\end{abstract}

Key-words: Population displacement; Climate Changes; Colombia.

Os deslocamentos populacionais de colombianos dentro e fora das fronteiras do país não são um fenômeno apenas da atualidade. A região é marcada por desníveis socioeconômicos preocupantes e um conflito interno de quase 50 anos de origem político-econômica, que são responsáveis pela posição da Colômbia, até 2008, em segundo lugar no número de deslocados internos ${ }^{3}$ (ACNUR, 2013).

O conflito civil tem em sua origem demandas por mudanças na distribuição agrária, reforma política e melhorias sociais (VILLA, 2008). A situação de violência perdura até hoje e gera instabilidade em toda a região andina por seu envolvimento com

\footnotetext{
${ }^{1}$ Artigo recebido em 04 de junho de 2013 e aprovado para publicação em 03 de outubro de 2013.

2 Mestranda em Relações Internacionais, San Tiago Dantas (UNESP-UNICAMP-PUC/SP). Membro do Núcleo de Estudo e Pesquisa sobre Deslocados Ambientais (Nepda -UEPB). São Paulo, Brasil.

3 Deslocamentos que permanecem dentro do território nacional (ACNUR).
} 
o narcotráfico e por motivar a saída de colombianos para países vizinhos em busca de paz. Venezuela, Panamá e Equador são destinos de centenas de colombianos (NCR, 2013) e fazem parte da chamada Situação Colômbia, que visa repartir as responsabilidades da proteção aos deslocados colombianos (ACNUR, 2012).

Além da existência de um conflito civil duradouro, nas últimas décadas a região vem sofrendo com os impactos das alterações climáticas no meio ambiente. Estas que também se tornaram um fator que influencia nos deslocamentos populacionais (OMI, 2013). Tanto que em 2010, o país estava entre os três cujos deslocamentos eram mais afetados por mudanças climáticas (SANDNÆS, 2011). 0 país ainda sofre com um nível de vulnerabilidade moderada, com altos riscos de desastres climáticos (BARAJAS, 2012).

Os principais problemas climáticos que assolam a Colômbia são resultantes de fenômenos como o La Niña, que gera fortes chuvas (SANDNÆS, 2011) e o derretimento das geleiras (KAENZIG et al. 2013, p. 53), os quais, de acordo com o Intergovernmental Panel on Climate Change (IPCCH) apud Kaenzig et al. (2013, p. 50-1) podem produzir um efeito significativo nos deslocamentos populacionais.

As consequências do La Niña foram observadas na catástrofe ocorrida na Colômbia em 2010, que afetou 93\% dos municípios do país. A situação se deteriorou em 2011, quando o fenômeno reapareceu e causou mais inundações, deslizamentos de terra afetando mais de 3 milhões de pessoas, milhares de hectares cultiváveis alagados, além de estradas, reservatórios de água e propriedades destruídas (REFUGEES INTERNATIONAL, 2012; SANDNÆS, 2011; KNIVETON \&PORTILLA, 2012).

Segundo a SANDNÆS (2011), cerca de 2.294.402 milhões pessoas foram deslocadas e mais de 440 mil casas foram destruídas. 0 abastecimento de água e de serviços básicos teve, inclusive, que ser interrompido por determinado tempo. Diante do desastre, Juan Santos, presidente do país, lançou a operação Colombia Humanitaria, uma campanha para arrecadar fundos para auxiliar as vítimas. Todavia, poucos receberam os benefícios. Justamente os mais prejudicados foram os grupos sociais mais fragilizados, que habitavam áreas remotas, afastadas e dominadas pelo longo conflito civil (REFUGEES INTERNATIONAL, 2012).

Além das inundações, de acordo com o IPCCH (2007), áreas como os Andes, que dependem do derretimento de neve armazenada no inverno, podem sofrer impactos 
significativos na disponibilidade de recursos hídricos com o derretimento das geleiras, que segundo Malta (2011, p.174), a longo prazo, pode interferir na falta de irrigação e na diminuição da produção de alimentos. Werz e Conley (2012, p. 6-7) acrescentam ainda que,

[t]he average rate of glacial melting has doubled over the past few years, according to the World Glacier Monitoring Service. [...] a number of other Andean countries will be massively affected, including [...] Colombia. This development will put water security, agricultural production, and power generation at risk-all factors that could prompt people to leave their homes and migrate.

Além disso, de acordo com a Organização Comunidade Andina (2013), apesar de a região ser uma área com pouca produção de gases de efeito estufa (2,5\%), está sofrendo fortemente seus efeitos devido à fragilidade de seus ecossistemas e da situação social do país. As consequências do aumento da temperatura vão interferir na sobrevivência de inúmeras espécies, no abastecimento de água e de energia, visto que aproximadamente $60 \%$ da eletricidade dos países andinos é proveniente de hidroelétrica.

O maior desafio no país é o estabelecimento de padrões de proteção mais elaborados para os deslocados por questões ambientais. Na realidade, a maior parte dos deslocamentos ocasionados por mudanças climáticas ocorre no âmbito interno; desta forma, muitos indivíduos poderiam ser abarcados pelo Guia de Princípios em Deslocamento Interno, que já inclui a categoria dos migrantes por desastres naturais. No entanto, a Colômbia não reconhece os deslocados por desastres naturais como uma categoria que necessita de proteção (SANDNÆS, 2011). No âmbito das Nações Unidas, a proteção aos deslocados ambientais ainda não existe. Todavia, ações em busca de assegurar a mitigação desta ausência são encontradas, por exemplo, na iniciativa Nansen ${ }^{4}$ (WALTER, 2012).

Kniveton e Portilla (2012, p. 34) destacam que apesar de não existir nenhuma documentação sobre a relação entre mudança climática e migração no país, a maior parte dos migrantes é proveniente de regiões que sofrem com as mudanças climáticas,

\footnotetext{
${ }^{4}$ Lançada em outubro de 2012, a iniciativa pretende criar um consenso entre os países sobre a melhor forma de lidar com os deslocamentos resultantes de desastres naturais.
} 
como Valle del Cauca, Eje Cafetero e a Costa Atlantica. É inegável que os deslocamentos são principalmente motivados pelo conflito civil e pela existência de um poder paralelo exercido pelos grupos guerrilheiros e paramilitares que intimidam a população (CODHES, 2011), mas não se pode ignorar a influência dos fatores ambientais, que também importam. Os deslocamentos têm, na realidade, múltiplas causas. De acordo com Kaenzig et al. (2013, p.59), a frágil realidade socioeconômica da Colômbia a torna mais vulnerável a esses fatores ambientais.

Wilches (2012, p.28) ainda apresenta outro fator motivacional para os deslocamentos: a expulsão dos indivíduos de suas terras para a plantação de palma africana - entre outras plantas - destinada à fabricação de agrocombustíveis, que, junto com a atividade mineradora, são responsáveis por sérios problemas ambientais no país em termos de poluição.

Observa-se, assim, que além dos problemas socioeconômicos já preocupantes, a Colômbia precisa lidar com outros problemas ambientais que também influenciam nos deslocamentos populacionais. As mudanças climáticas estão acarretando consequências que problematizam ainda mais essa situação. Espera-se que o governo conscientize-se desta relação entre as migrações e os problemas ambientais e tome medidas para mitigar seus efeitos.

\section{Referências Bibliográficas}

ACNUR. Deslocados Internos. Disponível em: <http://www.acnur.org/t3/portugues/aquem-ajudamos/deslocados-internos/?L=kzziabdyuyhoavqj> Acesso em 03 de outubro de 2013. . 2012. Situación Colombia. Disponível em: <> Acesso em 03 de outubro de 2013

BARAJAS, Diana. Climate Change and Vulnerability: na Analysis of Colombian Case. Disponível em: <http://www.eoi.es/blogs/dianapatriciasanchez/2012/02/10/climate-changeand-vulnerability-an-analysis-of-colombian-case/> Acesso em 16 de abril de 2013.

CNR. Consejo Noruego para Refugiados. Dia Mundial de los Refugiados. 2013. Disponível em: < http://www.nrc.org.co/> Acesso em 03 de outubro de 2013.

COMUNIDADE ANDINA. Environment 2013. Disponível em: <http://www.comunidadandina.org/en/seccion2.aspx?id=132\&tipo=TE\&title=clim ate-change $>$ Acesso em 16 de abril de 2013.

IOM. Colombia. $2013 . \quad$ Disponível em: <http://www.iom.int/cms/render/live/en/sites/iom/home/where-we- 
work/americas/south-america/colombia.html\#mcced> Acesso em 16 de abril de 2013.

IPCCH. Magrin, G., C. Gay García, D. Cruz Choque, J.C. Giménez, A.R. Moreno, G.J. Nagy, C. Nobre and A. Villamizar. Climate Change 2007: Impacts, Adaptation and Vulnerability. Cambridge University Press. Disponível em: <http://www.ipcc.ch/pdf/assessment-report/ar4/wg2/ar4-wg2-chapter13.pdf> Acesso em 03 de outubro de 2013.

KAENZIG, Raoul; PIGUE, Etienne. Migração e Mudança Climática em América Latina. 2011. Disponível em:

<http://www.csem.org.br/remhu/index.php/remhu/article/viewFile/247/229> Acesso em 15 de abril de 2013.

KALIM, Walter. De los Principios de Nansen a la Iniciativa Nansen.2012. Disponível em: < http://www.fmreview.org/es/prevencion/kaelin> Acesso em 03 de outubro de 2013.

KNIVETON, Dominic; PORTILlA, Jason Garcia. Impactos del cambio climático y evidencia de migraciones en Colombia. 2012. Disponível em: $<$ http://observatoriodemigraciones.org/apc-aa-

files/69e3909999fd8ec8018dd3f5d7dbdc5d/DMigrantesNo.8.pdf> Acesso em 16 de abril de 2013.

MALTA, Fernando. A Anomalia da Anomalia: Os refugiados ambientais como problemática teórica, metodológica e prática. 2011. Disponível em: <http://www.csem.org.br/remhu/index.php/remhu/article/viewFile/253/235> Acesso em 15 de abril de 2013.

REFUGEES INTERNATIONAL. Colombia: Flood Response Improves, But Challenges Remain. 2012. Disponível em: < http://www.refugeesinternational.org/policy/fieldreport/colombia-flood-response-improves-challenges-remain > Acesso em $11 \mathrm{de}$ maio de 2013.

SANDNES, Ingrid Christine. Severely affected by climate change. 2011. Disponível em: < http://www.nrc.no/?did=9570042> Acesso em 11 de maio de 2013

VILLA, Rafael Duarte; VIANA, Manuela Trindade. A ascensão de Uribe na Colômbia: Segurança Interna e Aliança Estratégica com os Estados Unidos na Construção do Estado-Nação. In: Novas lideranças políticas e alternativas de governo na América do Sul. São Paulo, 2008.

WERZ, Michael; CONLEY, Laura. Climate Change, Migration, and Conflict: Addressing complex crisis scenarios in the 21st century. 2012. Disponível em: <http://www.americanprogress.org/wpcontent/uploads/issues/2012/01/pdf/cli mate_migration.pdf $>$ Acesso em 16 de abril de 2013.

WILCHES, Víctor. Cambio Climático y Cenit del Petróleo: Caminando hacia el Colapso. 2012. Disponível em: <http://observatoriodemigraciones.org/apc-aafiles/69e3909999fd8ec8018dd3f5d7dbdc5d/DMigrantesNo.8.pdf> Acesso em 16 de abril de 2013. 